\title{
ANALISIS PENGELOLAAN KOLEKSI NASKAH KA-GA-NGA DI MUSEUM BENGKULU
}

\author{
Muhardi \\ Museum Negeri Bengkulu \\ Jl. Pembangunan No. 08, Gading Cempaka, Kota Bengkulu, \\ Muhardibgdsutan@gmail.com
}

\begin{abstract}
Analysis of Management of Ka-Ga-Nga Manuscript in Bengkulu Museum. Ka-Ga-Nga manuscript is one of heritage which describes social and cultural lifes of Bengkulu as a cultural community. Nowadays, the cultural values of the $\mathrm{Ka} G a \mathrm{Nga}$ manuscript are still growing up such as custom, farming, medical treatment (therapy), traditional ceremony and beliefs; therefore, the $\mathrm{Ka} \mathrm{Ga} \mathrm{Nga}$ manuscript need to be preserved. The preservation includes storing, utilizing and developing of the Ka-Ga-Nga manuscript as Bengkulu identity. Qualitative method with descriptive qualitative analysis has been done to the $\mathrm{Ka}$ - Ga-Nga manuscripts collection management at Bengkulu Museum particularly on the preservation, storage, and display. The results of this research indicate the collection management of the Ka-Ga-Nga manuscript at Bengkulu is less optimal due to the human resources which are incompetence to manage manuscript. As a consequence, the values of manuscript collections are not well socialized. Therefore, the Bengkulu Museum management on the Ka-Ga-Nga manuscript collections organized by cataloguing the manuscript, doing research, making data base of information, and optimizing the museums program through exhibition and socialization. These efforts will support the museum to be a pioneer for the perpetuation of the Ka-Ga-Nga manuscript and Bengkulu Culture.
\end{abstract}

Keywords : manuscript, management, preservation, storage, display.

\begin{abstract}
Abstrak: Analisis Pengelolaan Koleksi Naskah Kaganga di Museum Bengkulu. Naskah Ka-Ga-Nga adalah karya tulis hasil budaya masa lampau yang menceritakan tentang kehidupan sosial budaya masyarakat Bengkulu sebagai satu komunitas budaya. Sebagian dari nilai budaya yang terdapat di dalam naskah tersebut masih tumbuh dan berkembang dalam kehidupan masyarakat saat ini seperti adat istiadat, pertanian, pengobatan, upacara tradisi, dan kepercayaan, karena itu naskah $\mathrm{Ka}-\mathrm{Ga}-\mathrm{Nga}$ merupakan dokumentasi yang perlu dilestarikan. Pelestarian meliputi penyelamatan, pemanfaatan dan pengembangan naskah Ka- Ga-Nga yang merupakan identitas Bengkulu. Analisis data secara deskriptis terhadap pegelolaan koleksi naskah Ka-Ga-Nga di Museum Bengkulu, terutama dalam, perawatan, penyimpanan, penyajian, dan pengolahan informasi dengan melakukan pengamatan dan wawancara dengan pengelola museum serta pemerhati budaya tentang naskah $\mathrm{Ka}-\mathrm{Ga}-\mathrm{Nga}$ di Bengkulu. Hasil penelitian menunjukkan bahwa pengelolaan koleksi naskah $\mathrm{Ka}-\mathrm{Ga}-\mathrm{Nga}$ di Museum Bengkulu belum dilaksanakan secara optimal disebabkan terbatasnya sumber daya, khususnya dalam pengelolaan naskah. Akibatnya koleksi naskah kurang mendapat perhatian dari pengunjung museum, sehingga nilai-nilai yang terkandung di dalamnya juga belum memasyarakat. Dengan demikian Museum Bengkulu harus dapat meningkatkan pengelolaan koleksi naskah $\mathrm{Ka}-\mathrm{G} a-\mathrm{Ng} a$ melalui penyusunan katalog, pengkajian, penyempuraan sistem penyajian, dan pemanfaatan teknologi informasi dalam publikasi, sehingga dapat menjadi pelopor pelestarian naskah Ka-Ga-Nga khususnya dan budaya Bengkulu umumnya.
\end{abstract}

Kata kunci : Naskah, pengelolaan, perawatan, penyimpanan, penyajian.

\section{Pendahuluan}

Museum Bengkulu merupakan salah satu institusi kebudayaan yang memiliki peran strategis dalam melestarikan (perlindungan, pemanfaatan, dan pengembangan) warisan sejarah budaya khususnya daerah Bengkulu. Diantara hasil budaya Bengkulu yang lahir dari keanekaragaman subetnis penduduk aslinya itu adalah naskah Ka-Ga-Nga. Diharapkan Museum Bengkulu menjadi pelopor dan motor penggerak upaya pelestarian naskahKa-Ga-Nga. 
Istilah Ka-Ga-Nga pertama kali dipakai oleh Jaspan antropolog yang pernah meneliti masyarakat suku Rejang pada tahun 1961-1964, untuk menyebutkan aksara yang dipakai oleh masyarakat Rejang, Serawai, Pasmah, Lembak (di Bengkulu) serta Lampung. ${ }^{1}$ Nama ini kemudian menjadi terkenal dan lebih familiar bagi masyarakat Bengkulu dari pada naskah atau sastra Ulu atau naskah Rencong yang merupakan penamaan oleh sarjana- sarjana Belanda seperti, Stutler 1855 dan 1843; Heferich 1904; dan Westenenk 1919, 1920, dan 1921.

Bahan/material yang digunakan sebagai media untuk menulis adalah bambu, bilah bambu (gelumpai), rotan, kulit kayu, tanduk, batu, dan juga kertas. Bahasa yang dipakai adalah bahasa Rejang, Serawai, dan Melayu, ditemukan pula naskah $\mathrm{Ka}-\mathrm{Ga}-\mathrm{Nga}$ yang ditulis dengan menggunakan bahasa campuran Rejang, Serawai, Melayu, dan Lembak. ${ }^{2}$ Isi naskah Ka-Ga-Nga ialah hukum adat, pengobatan, doa dan mantra, kisah/kejadian, tembo atau silsilah, rejung dan perambak (sejenis puisi/pantun mudamudi), serta cerita rakyat. ${ }^{3}$

Koleksi naskah Ka-Ga-Nga Museum Bengkulu tercatat sebanyak 146 (seratus empat puluh enam) koleksi. Untuk mengelola koleksi tersebut, dibutuhkan ketekunan, ketelitian, dan kemauan yang keras karena pengelolaan naskah menyangkut banyak aspek dan bersifat multidisiplin. Penelitian ini bertujuan : (1) mendeskripsikan dan menganalisis pengelolaan koleksi naskah $\mathrm{KaGa-Nga}$ di Museum Bengkulu. (2) menghasilkan konsep atau rancangan pengelolaan koleksi naskah $\mathrm{Ka}-\mathrm{Ga}-\mathrm{Nga}$ yang dapat dijadikan sebagai pedoman oleh Museum Bengkulu.

\section{Pembahasan.}

\section{Metode Analisis}

Untuk menganalisis permasalahan dan tujuan yang ingin dicapai dalam penelitian ini digunakan metode kualitatif yang menghasilkan data bersifat deskriptif berasal dari wawancara, observasi, dan studi lapangan. Wawancara dilakukan terhadap pengelola museum terutama yang berhubungan dengan pengelolaan koleksi (registrar, konservator dan preparator, kurator, dan edukator), pemerhati budaya, serta pengunjung.

Data penelitian yang didapat melalui observasi, wawancara, dan studi kepustakaan, kemudian diklasifikasi dan dianalisis secara kualitatif. Disamping itu dilakukan juga pendekatan managemen, komunikasi, dan filologi untuk menemukan sistem penyajian koleksi dalam rangka sosialisasi koleksi kepada masyarakatkan, sebagai bagian dari pelestarian.

2. Analisis Pengelolaan Koleksi

Pengelolaan koleksi adalah serangkaian kegiatan yang dilakukan secara berurutan dan menyangkut berbagai macam aspek kegiatan, dimulai dari pengadaan koleksi, registrasi dan inventarisasi, perawatan, penelitian sampai koleksi tersebut disajikan di ruang pamer atau disimpan pada ruang penyimpanan koleksi. ${ }^{4}$

a. Analisis Pengadaan Koleksi

Pengadaan koleksi adalah kegiatan pengumpulan benda realia atau replika setelah dilakukan survei koleksi dan dinyatakan benda tersebut menjadi koleksi museum yang berkualitas sebagai bahan sejarah alam, budaya, manusia serta lingkungannya dari wilayah Nusantara yang dapat menggambarkan identitas kesatuan bangsa. ${ }^{5}$

Pengadaan koleksi naskah $\mathrm{Ka}-\mathrm{Ga}$ Nga di Museum Bengkulu dilaksanakan melalui proses ganti rugi (imbal jasa), juga ada beberapa naskah yang didapatkan melalui hibah dari keluarga pemilik naskah. Pengadaan koleksi dilaksanakan untuk melengkapi koleksi yang sudah ada sesuai dengan kreteria dan ketentuan pengadaan koleksi museum. Selanjutnya dijelaskan bahwa pengadaan koleksi naskah selalu menjadi prioritas karena 


\section{Muhardi \\ Analisis Pengeldaan Koleksi Naskah Kaganga di Museum Bengkulu}

naskah termasuk koleksi khusus yang langka dan sulit ditemukan. Bahkan prosesnya terkadang tidak melalui prosedur survei pengadaan koleksi terlebih dahulu.

Upaya yang dilakukan oleh Museum Bengkulu untuk menyelamatkan naskah melalui pengadaan koleksi dapat dikatakan maksimal, namun tercipta kesenjangan karena dokumentasi yang dilakukan belum menghasilkan data yang lengkap. Kondisi ini menyebabkan terbatasnya informasi sebagian koleksi yang didapatkan, sementara dokumentasi koleksi adalah data awal untuk proses pengelolaan buku registrasi dan inventaris koleksi, di samping laporan survei pengadaan koleksi. Untuk mengatasi hal ini, perlu dilakukan penelusuran ulang pengkajian pelaksanaan pengadaan koleksi tersebut. Dengan pengumpulan data ini maka diharapkan semua informasi yang berhubungan dengan koleksi akan terungkap sehingga museum akan mempunyai dokumentasi lengkap.

b. Analisis Registrasi Koleksi

Registrasi merupakan suatu kegiatan pencatatan koleksi ke dalam buku registrasi oleh registrar. dalam rangka pengamanan atau untuk mengidentifikasi benda yang menjadi koleksi museum. Kegiatan ini meliputi pembuatan nomor registrasi, pengisian buku registrasi, pembuatan kartu registrasi, dan label registrasi. Tindakan pertama yang dilakukan terhadap benda itu adalah memberi nomor registrasi. Tujuan penomoran adalah pengamanan koleksi secara umum, dan administrasi secara khusus.

Kartu registrasi memuat data: nomor registrasi, nomor inventaris, nama koleksi, tempat pembuatan, tempat perolehan, cara perolehan, ukuran, tanggal/tahun masuk, keterangan dan uraian singkat dibuat di belakang kartu. Semua item tersebut dibuat dalam kolom, diisi dengan jelas dan ringkas, dilengkapi foto koleksi. Label registrasi berisi nomor registrasi, nomor inventaris, dan nama koleksi. Label koleksi digantungkan pada koleksi dengan tujuan agar koleksi tidak tertukar dalam penyimpanan. Jika koleksi dipamerkan, labelnya harus dilepas. Label koleksi tidak boleh dituliskan di koleksi karena pada koleksi hanya terdapat nomor inventaris koleksi.

Pengerjaan buku registrasi koleksi Museum Bengkulu sudah dilakukan, namum masih terdapat kolom yang kosong seperti waktu pengadaan, asal koleksi, uraian singkat. Hal ini disebabkan kurang lengkapnya data yang didapatkan oleh registrar dari tim pengadaan koleksi yang bersumber dari sistem pengadaan koleksi yang terkadang tidak melalui tahapannya. Untuk melengkapi data ini, perlu dilakukan peninjauan kembali melalui penelusuran riwayat dan tujuan pengadaan koleksi dalam kegiatan herregistrasi.

c. Analisis Inventarisasi Koleksi

Inventarisasi koleksi adalah suatu kegiatan pencatatan benda-benda koleksi museum ke dalam buku inventaris koleksi yang mempunyai formatformat tertentu, datanya berasal dari buku registrasi. Penulisan data pada buku inventaris lebih rinci dari buku registrasi. ${ }^{6}$ Buku inventaris koleksi terdiri dari buku induk inventaris koleksi dan buku inventaris koleksi. Buku inventaris koleksi dikelola oleh kurator dan hanya mencatat data satu jenis koleksi saja.

Data yang termuat dalam buku inventaris koleksi, antara lain, nomor inventaris, nomor registrasi, nama koleksi, uraian singkat, tempat pembuatan, tempat perolehan, ukuran, tanggal/tahun masuk, penempatan, dan keterangan. Dalam buku inventaris koleksi filologika Museum Bengkulu masih terdapat beberapa keterangan yang kosong seperti : asal naskah, tahun pengadaan, uraian singkat/ isi teks. Terdapat 38 koleksi yang tidak diketahui daerah asalnya. Di samping itu, masih ada koleksi yang tidak memuat keterangan lain seperti bahasa, tahun 
masuk, uraian ringkas dan ciri-ciri lainnya. Kondisi ini disebabkan kurang lengkapnya data pada kartu registrasi koleksi. Untuk melengkapi data perlu dilakukan re-inventarisasi yang didasarkan pada penelitian lanjutan untuk mendapatkan data yang lebih lengkap.

Dalam tulisan ini penulis mengklasifikasikan naskah $\mathrm{Ka}-\mathrm{G} a-\mathrm{Ng} a$ berdasarkan materil naskah seperti tergambar dalam diagram berikut ini :

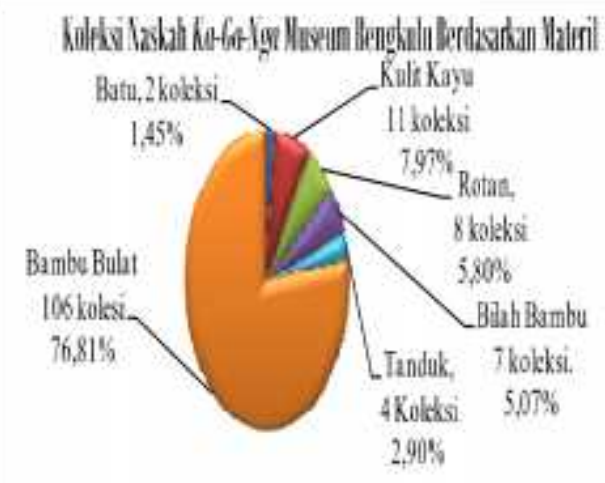

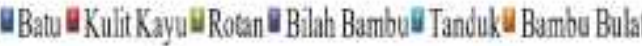

Koleksi naskah Ka-Ga-Nga berdasarkan bahan / materil

Dari diagram tersebut, bahan yang terbanyak adalah bambu bulat atau bambu gelondongan yang jumlahnya mencapai 106 koleksi. Bambu adalah bahan yang mudah didapat karena banyak tersedia di lingkungan sekitar mereka.

Permukaan bambu yang keras dan licin sebagai media tempat menulis aksara terlihat sesuai dengan bentuk huruf yang kaku, sepertinya terdapat hubungan antara bahan dan bentuk hurufnya. Di Bengkulu bambu juga banyak dipakai untuk bahan bangunan, dan peralatan rumah tangga seperti periyan yaitu wadah untuk membawa air bersih guna keperluan memasak. Bambu dan sejenisnya dalam kehidupan masyarakat Bengkulu juga mempunyai makna falsafah seperti antara lain tertuang dalam pepatah : ibarat membelah bambu, seperti aur dengan tebing, rebung tidak jauh dari induknya.
Pengelompokan berdasarkan isi dan bahasa perlu bantuan dari filolog dan ahli yang mengerti tentang aksara $\mathrm{Ka}-\mathrm{Ga}-\mathrm{Nga}$. Pengelompokan ini sangat membantu untuk memahami naskah secara utuh seperti persebaran naskah, hubungan antara bahan, isi, asal, bahasa dan aspek lainnya. Hal ini belum dilakukan karena terbatasnya sumber daya kurator di Museum Bengkulu.

\section{d. Katalogisasi}

Katalogisasi koleksi sangat diperlukan sebagai salah satu upaya untuk memperkenalkan koleksi. Katalogisasi koleksi menurut Kamus Peristilahan Museum (Direktorat Permuseuman, 2001: 11) adalah kegiatan pencatatan data mengenai identitas koleksi pada format tertentu, sedangkan menurut buku Pedoman Pengelolaan Museum yang diterbitkan oleh Departeman Kebudayaan dan Pariwisata (2007: 32) kartu katalog koleksi museum mencatat data/informasi seperti 1) nama dan alamat museum, 2) nomor inventaris/ketalogus, 3) nama benda, 4) Deskripsi, 5) ukuran dan timbangan, 6) tempat asal, 7) kurun waktu /jaman, 8) cara mendapatkannya /pengadaannya, 9) tanggal pengadaannya, 10) lokasi penyimpanan di Museum, 11) Referensi publikasi/informasi, 12)

keterangan lain-lain.

Berdasarkan pengertian tersebut katalogisasi koleksi naskah Ka-Ga-Nga adalah suatu kegiatan membuat deskripsi dan identifikasi tentang naskah $\mathrm{Ka}-\mathrm{GaNga}$ ke dalam buku katalog. Katalog naskah merupakan langkah awal untuk penelitian filologi karena di dalamnya telah terdapat uraian singkat deskripsi naskah. Katalog koleksi naskah $\mathrm{Ka}-\mathrm{G} a-\mathrm{Nga}$ belum pernah disusun museum Bengkulu karena belum semua naskah yang dibaca, sementara filolog ataupun orang yang dapat membaca aksara $\mathrm{Ka}-\mathrm{G} a-\mathrm{Nga}$ tidak ada di Museum Bengkulu.

Tersedianya katalog naskah $\mathrm{Ka}-\mathrm{Ga}$ Nga di Museum Bengkulu memungkinkan 


\section{Muhardi}

masyarakat dapat mengakses data naskah dengan mudah, sementara dari pihak museum penyebaran informasi naskah pada masyarakat dapat terselenggara lebih maksimal. Hal lain yang tak kalah penting adalah dengan adanya katalog ini, langkah awal penelitian filologi sudah dimulai karena katalog juga berfungsi sebagai media publikasi dari naskah. Selanjutnya, katalog naskah Ka-Ga-Nga juga dapat dimanfaatkan sebagai sumber belajar sastra daerah atau budaya daerah bagi pelajar dan mahasiswa.

e. Analisis Perawatan Koleksi

Perawatan koleksi naskah di museum pada dasarnya adalah usaha penyelamatan naskah secara fisik dan konten/isi dari naskah (pelestarian). Secara alamiah koleksi museum akan mengalami proses degradasi, yaitu proses penurunan kualitas berupa kerusakan yang disebabkan oleh faktor dari benda itu sendiri (internal) dan pengaruh lingkungan alam diluar koleksi (eksternal) seperti kelembapan udara, perubahan suhu, debu, polusi udara, cahaya, serangan serangga, dan manusia. Kondisi ini juga berlaku pada benda-benda yang sudah dirawat karena itu perawatan koleksi harus dilakukan secara berkesinambungan.

Diperlukan ketelitian dalam pelaksanaan perawatan koleksi naskah sesuai prinsip pelestarian naskah yang terdiri dari aspek fisik dan isi. Seksi koleksi konservasi dan preparasi melakukan perawatan koleksi berdasarkan skala perioritas kondisi fisik koleksi yang harus dilakukan tindakan perawatan, hal ini terjadi karna terbatasnya dana dan juga sumber daya manusianya.

Materil/bahan koleksi naskah KaGa-Nga Museum Bengkulu yang berasal dari bahan organik seperti bambu, kulit kayu, tanduk, rotan umumnya rusak secara alamiah dan kimia, gangguan jamur dan serangga adalah penyebab utamanya. Fumigasi adalah cara pembasmian yang efektif dalam penanganan naskah. Bahan yang digunakan untuk fumigasi disebut fumigant. Dalam keadaan tertentu zat kimia yang berbentuk gas ini pada konsentrasi tertentu dapat mengganggu pernafasan serangga dan pertumbuhan jamur. $^{7}$

Setelah dilakukan fumigasi bukan berarti tugas perawatan sudah selesai, bahan organik masih perlu dirawat secara rutin seperti perbersihan dari debu, pengendalian lingkungan penyimpanan seperti kelambapan udara. Fumigasi, penyemprotan, dan penyusupan terhadap koleksi naskah di Museum Bengkulu belum pernah dilakukan karena secara umum kondisi fisik koleksi cukup baik.

Tindakan lain yang lebih aman dalam menangani koleksi naskah adalah melalui vakum yaitu proses sterilisasi fisik/materiel naskah. Tindakan ini dipandang aman karena tidak mengunakan bahan kimia sehingga cocok untuk preservasi koleksi sebagai tindakan preventif dengan proses vakum. Koleksi yang akan dirawat dimasukkan ke dalam tempat khusus yang hampa udara dan disimpan dalam waktu tertentu sehingga semua organisme yang ada dalam koleksi naskah akan mati karena tidak mendapatkan oksigen untuk pernafasannya. Tindakan ini juga belum pernah dilakukan Museum Bengkulu. Ke depan diharapkan hal ini dapat menjadi perhatian dari pihak museum dalam rangka menyelamatkan koleksi dari kerusakan yang lebih berat terutama koleksi naskah.

Koleksi yang rusak berat belum dilakukan perawatan karena sumber daya manusia dan peralatan teknis yang tersedia di Museum Bengkulu belum memadai. Oleh karena itu, perlu kerja sama dengan pihak ketiga seperti Balai Konservasi DKI. Dengan kondisi ini kiranya untuk masa yang akan datang museum perlu membuat perencanaan kerja sama dengan pihak ketiga dalam 
menangani koleksi yang harus mendapatkan tindakan perawatan khusus.

f. Analisis Penyimpanan Koleksi

Koleksi museum selalu bertambah karena adanya pengadaan koleksi, sementara tidak semua koleksi itu dipamerkan atau dikomunikasikan pada masyarakat. Untuk itu, diperlukan tempat khusus yang dalam teknis permuseuman disebut storage. Koleksi yang disimpan di storage (ruang penyimpanan koleksi) adalah koleksi yang telah steril, ditempatkan pada lemari rak khusus sesuai dengan jenis klasifikasi koleksi dan materilnya dan dikontrol secara periodik oleh petugas storage. ${ }^{8}$

Penyimpanan koleksi naskah $\mathrm{Ka}-\mathrm{Ga}$ Nga ditempatkan pada satu lemari khusus. Koleksi ditumpuk pada rak di dalam lemari penyimpanan, tidak ada pemisahan berdasarkan materil/bahan, koleksi dibiarkan terbuka tanpa dibungkus, tidak dilengkapi dengan silicagel. Walaupun lemari selalu tertutup rapat, dengan cara penyimpanan seperti ini dikhawatirkan koleksi akan rusak dalam jangka waktu tertentu karena pengaruh alam, mengingat kota Bengkulu terletak di daerah pantai. Kelembapan udara kota Bengkulu berkisar antara 81 - 86 persen, temperatur rata-rata $26^{\circ} \mathrm{C}$, tekanan udara rata-rata antara 1008 - $1011 \mathrm{mb}$, dan penguapan rata-rata antara 4,2-5,0 mm.

Untuk menanggulangi pengaruh alam terhadap koleksi naskah yang berasal dari bahan organik, seharusnya koleksi dibungkus dengan kertas bebas asam atau dibuatkan kotak dari karton kertas bebas asam. Selanjutnya disusun secara teratur. Tindakan ini juga untuk menghindarkan persentuhan/gesekan langsung antara koleksi yang akan menyebabkan kerusakan berupa goresan/lecet yang mengakibatkan rusaknya tulisan pada naskah.

Penyusunan koleksi pada rak penyimpanan sebaiknya dipisahkan menurut meteril naskah, juga dipisahkan antara naskah yang telah ditransliterasi atau diteliti. Hal ini dimaksudkan untuk memudahkan identifikasi ulang koleksi. Di samping itu, yang perlu mendapat perhatian adalah data koleksi sebaiknya dibuat dalam bentuk data base yang memuat secara rinci tentang satu koleksi termasuk tempat penyimpanannya agar memudahkan pelacakan jika koleksi itu dibutuhkan. Untuk keteraturan administrasi koleksi di storage dan memudahkan pencarian koleksi, perlu dibuat kartu kendali dan kartu simpan. Kartu kendali belum disediakan, hanya saja pada waktu keluar masuk koleksi selalu dibuat berita acara. Hal ini karena belum tuntasnya pelaksanaan reinventarisasi koleksi secara keseluruhan. Demikian juga dengan pengontrolan rutin secara berkala untuk semua koleksi akan ditingkatkan.

g. Analisis Penyajian

Pameran tetap Museum Bengkulu menyajikan lima ratusan koleksi benda sejarah dan budaya Bengkulu. Koleksi ditata pada vitrin terbuka dan vitrin kaca, boks, panel dan diorama penunjang displai. Displai pameran berupaya memberikan gambaran tentang kehidupan sosial dan budaya masyarakat Bengkulu dipadu lukisan sejarah dengan pendekatan estetis dan edukatif yang ditata pada dua lantai ruang pameran seluas $2.000 \mathrm{~m}$.

Penyajian naskah $\mathrm{Ka}-\mathrm{Ga}-\mathrm{Nga}$ di Museum Bengkulu dilakukan melalui pameran tetap dan pameran keliling, sedangkan penyajian dalam bentuk lain seperti sosialisasi secara khusus belum pernah dilakukan. Naskah Ka-Ga-Nga juga pernah dipamerkan pada pameran aksara Nusantara oleh Museum Nasional. Koleksi yang dipamerkan adalah naskah $\mathrm{Ka}-\mathrm{Ga}-\mathrm{Nga}$ pada batu.

Penyajian koleksi naskah $\mathrm{Ka}-\mathrm{Ga}-\mathrm{Nga}$ dalam pemeran tetap Museum Bengkulu tidak terlihat adanya tema khusus yang mangacu pada tema besar. Tidak jelas apakah berdasarkan isi, daerah asal naskah, bahasa yang digunakan dalam 


\section{Muhardi \\ Analisis Penge/alaan Kaleksi Naskah Kaganga di Musaum Bengkulu}

naskah ataupun berdasarkan bahan/materil naskah (naskah gelumpai/bilah bambu dan tanduk tidak dipamerkan). Demikian juga dengan kontens/isi naskah belum jelas keterkaitannya satu sama lain. Kondisi ini menyulitkan pengunjung memahami makna atau pesan yang tersimpul pada naskah. Pameran sekadar menampilkan koleksi naskah sebagai bagian dari peninggalan masa lalu.

Pameran hendaknya mempunyai tema yang jelas dan mengacu pada tema besar, displai ditunjang visualisasi dan dilengkapi informasi yang mudah dicerna. Agar pameran lebih manarik, pendekatan pameran adalah menggabungkan estetika, romantika, dan intelektual. Penyatuan ketiga metode ini dengan tema yang jelas akan melahirkan pameran yang menarik dan pesan yang ingin disampaikan melalui naskah bisa ditangkap pengunjung serta mereka mendapatkan pengalaman baru.

Tema kecil yang ditawarkan, misalnya "Aksara Ka-Ga-Nga dalam bingkai budaya Bengkulu masa lalu" atau "Kehidupan masa lalu dalam naskah $\mathrm{Ka}$ $\mathrm{Ga}-\mathrm{Nga}$ " dilengkapi dengan prolog yang ringkas dan jelas sebagai pengantar dapat membantu pengunjung memahami pameran. Label yang berfungsi untuk menjelaskan koleksi akan membantu pengunjung memahami keberadaan naskah pada masa lampau dan kaitannya dengan kekinian yang sedang kita lakoni.

Dalam situasi ini pengunjung dapat menggambarkan sendiri tata cara berkumunikasi nonverbal masyarakat pada masa lalu. Selanjutnya, menarik perbadingan dengan kehidupan sekarang seperti kearifan dan pengetahuan tentang diri dan lingkungannya. Di samping itu, juga dapat membantu pengunjung untuk menangkap dan memahami pesan yang disampaikan serta dapat membangun komunikasi kondusif antara museum dengan pengunjungnya.
Menurut hemat penulis, untuk membantu pengunjung memahami arti penting dari naskah $\mathrm{Ka}-\mathrm{Ga}-\mathrm{Nga}$ dan pemasyarakatannya, salah satu upaya adalah membuatkan semacam pedoman penggunaan aksara $\mathrm{Ka}-\mathrm{Ga}-\mathrm{Nga}$ dalam bentuk pengantar ringkas yang bisa dilampirkan pada transliterasi. Penunjung juga dilibatkan dalam kegiatan yang bersifat aplikatif. Kepada pengunjung diberikan cendra mata semacam pin untuk bros atau mainan kunci bergambar Museum Bengkulu, dan ada bagian untuk menulis nama pengunjung. Bahannya bisa bambu, kulit kayu yang digunakan sebagai materil naskah, atau bahan lainnya. Dengan demikian secara tidak langsung museum telah memberikan pengalaman dan pengetahuan tentang aksara $\mathrm{Ka}-\mathrm{Ga}-\mathrm{Nga}$ kepada pengunjung.

h. Labeling

Label adalah sarana komunikasi untuk memberikan informasi yang dimiliki oleh museum kepada pengunjung. ${ }^{9}$ Label memberikan suara pada koleksi tentang kepentingannya, keunikan-keunikannya, dan menceritakan sejarahnya yang dipresentasikan dengan bahasa yang ringkas dan sederhana untuk menyatakan aspek-aspek penting dalam objek pameran. ${ }^{10}$ Mengatakan bahwa label adalah pusat isi pendidikan dalam pameran.

Sebagaimana yang diungkapkan oleh beberapa pengunjung pameran koleksi naskah Ka-Ga-Nga belum dapat memenuhi keingintahuan pengunjung tentang naskah. Keterangan tentang koleksi yang dipamerkan (label) sangat singkat dan hanya menerangkan asal benda dan isinya. Pengunjung berharap dapat mengetahui bentuk dan sejarah tulisan, bahan, cara penulisan dan tempat penulisannya. Lebih jauh dijelaskan naskah $\mathrm{Ka}-\mathrm{Ga}-\mathrm{Nga}$ sebagai aset budaya daerah hendaknya dapat dimasyarakatkan dan dikembangkan agar menjadi salah satu ciri kebudayaan khas Bengkulu dan dikenal secara luas. Jika mungkin, 
dijadikan sebagai pelajaran budaya daerah yang dimasukkan dalam kurikulum muatan lokal agar generasi sekarang dapat menulis dan membaca

aksaraKa-Ga-Nga.

Pada kasus ini label akan berfungsi efektif jika dipadukan dengan keterangan tambahan semacam prolog yang mendukung seluruh penyajian. Prolog yang dimaksudkan di sini masih dalam konteks pengertian label. Dengan adanya prolog kalimat label dapat dibuat lebih singkat dan padat sehingga bisa dibaca dalam waktu yang lebih pendek. Keterangan tentang fisik koleksi tidak lagi diperlukan karena sudah terdapat pada prolog.

Pameran sebaiknya dilengkapi dengan visualisasi mengunakan multi media yang mendukung displai pameran dan disesuaikan dengan kebutuhan pengunjung. Disamping itu juga perlu ditingkatkan sosialisasi dalam bentuk seminar, workshop dan lain-lain terutama kepada generasi muda dan anak-anak yang disesuaikan dengan tingkat perkembangan mereka. Untuk anak-anak usia TK - SD dapat dilakukan dalam bentuk permainan seperti puzeel berupa susunan beberapa aksara Ka-Ga-Nga membentuk kata sederhana.

Dengan bantuan program multi media dan kegiatan aplikatif serta permainan yang bersifat edukatif, maka naskah yang secara fisik kurang menarik dapat menjadi lebih berkesan bagi pengunjung sehingga pada akhirnya diharapkan menjadi ikon koleksi. Semakin banyak media yang digunakan untuk mensosialisasikan koleksi naskah diharapkan pemahaman dan kecintaan masyarakat terhadap naskah dapat meningkat.

\section{Kesimpulan}

Pengelolaan koleksi naskah $\mathrm{Ka}-\mathrm{Ga}$ Nga di Museum Bengkulu belum dilakukan secara optimal baik secara administrasi maupun penanganan fisik berupa perawatan, penyimpanan dan penyajian. Perlu dilakukan her-registrasi dan re-inventarisasi berdasarkan penelusuran kembali riwayat pengadaan koleksi untuk mendapatkan data yang lengkap. Disamping itu juga peningkatan sistem perawatan dan penyajian mendesak untuk dilakukan agar kelestariannya dapat dipertahankan. Penyusunan katalog sangat dibutuhkan untuk menunjang publikasi naskah dan agar naskah lebih "bunyi" pemanfaatan teknologi informasi adalah alternatif yang sangat tepat dilakukan sehingga naskah dapat diakses secara luas tanpa terikat ruang dan waktu.

\section{Bentuk Grafem}

Kelompok Rejang dan Lembak

\begin{tabular}{|c|c|c|}
\hline No & Grafem & Bunyi \\
\hline 1 & 11 & $\mathrm{ka}$ \\
\hline 2 & 1 & ga \\
\hline 3 & 12 & nga \\
\hline 4 & $\Delta$ & ta \\
\hline 5 & $\Lambda_{1}$ & $\mathrm{da}$ \\
\hline 6 & 4 & na \\
\hline 7 & 1 & pa \\
\hline 8 & $T$ & $\mathrm{ba}$ \\
\hline 9 & $1 /$ & $\mathrm{ma}$ \\
\hline 10 & $\sigma$ & $\mathrm{ca}$ \\
\hline 11 & 11 & ja \\
\hline 12 & 11 & nya \\
\hline 13 & $y$ & sa \\
\hline 14 & 1 & la \\
\hline 15 & 11 & ya \\
\hline 16 & 1 & wa \\
\hline 17 & 1 & ha \\
\hline 18 & 11 & $\mathrm{a}$ \\
\hline 19 & 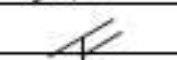 & $\mathrm{mba}$ \\
\hline 20 & 4 & nda \\
\hline 21 & 12 & nja \\
\hline 22 & $\pi$ & ngga \\
\hline 23 & $1 /$ & ngsa \\
\hline
\end{tabular}


Kelompok Serawai dan Pasmah

\begin{tabular}{|c|c|c|}
\hline No & Grafem & Bunyi \\
\hline 1 & 11 & $k a$ \\
\hline 2 & 1 & ga \\
\hline 3 & 12 & nga \\
\hline 4 & 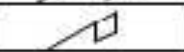 & ta \\
\hline 5 & $\pi$ & da \\
\hline 6 & 14 & na \\
\hline 7 & $1 /$ & $\mathrm{pa}$ \\
\hline 8 & $T$ & ba \\
\hline 9 & $1 K$ & $\mathrm{ma}$ \\
\hline 10 & $\sigma$ & $\mathrm{ca}$ \\
\hline 11 & 11 & ja \\
\hline 12 & 11 & nya \\
\hline 13 & 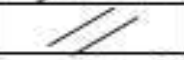 & sa \\
\hline 14 & 1 & la \\
\hline 15 & 12 & ya \\
\hline 16 & 11 & wa \\
\hline 17 & 11 & ha \\
\hline 18 & $T^{2}$ & $\mathrm{a}$ \\
\hline 19 & 11 & $\mathrm{ra}$ \\
\hline 20 & 4 & $\mathrm{mba}$ \\
\hline 21 & M & nda \\
\hline 22 & 11 & nja \\
\hline 23 & $A$ & ngga \\
\hline 24 & 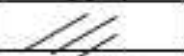 & ngsa \\
\hline 25 & $1 / 1 /$ & mpa \\
\hline 26 & 101 & $\mathrm{nca}$ \\
\hline 27 & 11 & nta \\
\hline 28 & 11 & ngka \\
\hline
\end{tabular}

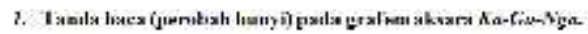

\begin{tabular}{|c|c|c|c|c|c|c|}
\hline No & 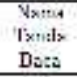 & $\begin{array}{l}\text { Bioniuk } \\
\text { 3anit } \\
\text { Bac1 } \\
\end{array}$ & $\begin{array}{c}\text { Ginaiem } \\
b\end{array}$ & $\begin{array}{l}\text { Jihki } \\
\text { cands } \\
\text { tack }\end{array}$ & 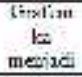 & Meutab yovis \\
\hline 1 & $T n \times n$ & $\because \ldots$ & 4 & 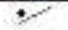 & $2 i$ & Bury $x$ mengat \\
\hline 2 & Tuling & $\rightarrow$ & & & $\mathrm{be}$ & Dreviameriade \\
\hline 5 & Yimis & $=\ldots$ & & & $2 a t$ & 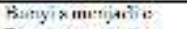 \\
\hline 1 & Ditm & & & & $x=$ & Imvameizu \\
\hline 5 & Mhinisi & $\therefore$ & & & $\mathrm{k} x$ & 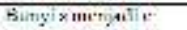 \\
\hline$s$ & Int $=5$ & ........ & & & $\mathrm{k}=\mathrm{s}$ & Inpyis mejid is \\
\hline 7 & Tulken & v.... & & & $\operatorname{lem}$ & Drwi a mevixd a \\
\hline $\mathrm{x}$ & 1):nistan & - & & & $k \times t$ & 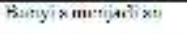 \\
\hline 9 & Kxning & $\ldots+4$ & & & kxm! & 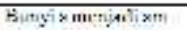 \\
\hline 10 & Juniung & $\ldots y$ & & & zar & Imwis mexixi \\
\hline 11 & $\lim \times x^{2}$ & $\cdots+1$ & & & $k \times x^{2}$ & 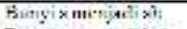 \\
\hline 12 & Eisu & -2 & & & $\mathrm{k}$ & Impiamemida \\
\hline 15 & Ruminh & & & & $i$ & 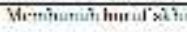 \\
\hline
\end{tabular}

2. Perbundiaran

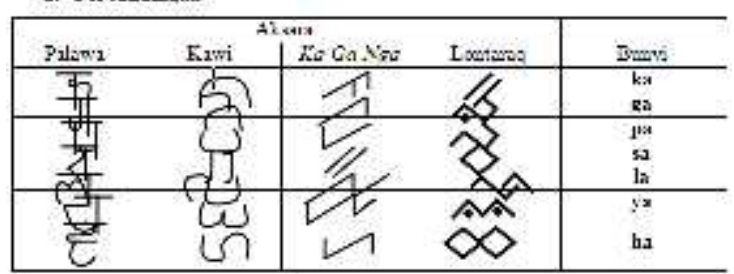

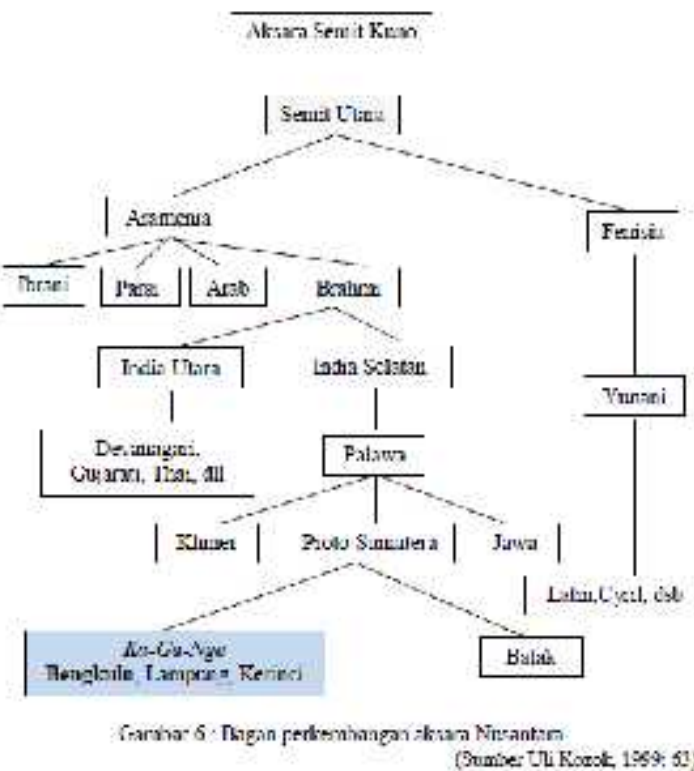

\section{Referensi}

${ }^{1}$ Astuti. 2000: 20

${ }^{2}$ IDKD, $1986: 131$

3IDKD, 1985/86 : 14.

${ }^{4}$ Dradjat, 2007 : 23.

5Departemen Kebudayaaan dan Pariwisata 2001:18.

${ }^{6}$ Dwiyanto, 2004:65.

7Razak, 1998: 1.

${ }^{8}$ Depbudpar, 2001: 7-9.

TTedjo, 1997: 20.

${ }^{10}$ Dean 1993: 109-110

Suharsimi Arikunto, Prosedur Penelitian Suatu Pendekatan Praktik, Rineka Cipta, Jakarta, 1986.

Nunuk Juli Astuti, Identifikasi NaskahNaskah Ulu Yang Tersimpan Di Museum Bengkulu. Laporan Penelitian Universitas Bengkulu. 2000.

Siti Baroroh Barried, dkk. Pengantar Teori Filologi, BPPF UGM, Jogjakarta Departemen Pendidikan dan Kebudayaan. 1986.

Inventarisasi Naskah Kuno Daerah Bengkulu. Proyek IDKD Kanwil Pd K Bengkulu, 1993/94.

Pedoman Buku Registrasi, Buku Induk Inventaris dan Buku Inventaris Koleksi Museum di Indonesia. Direktorat Museum. 2001.

Kamus Peristilahan Museum. 2007.

Pedoman Pengelolaan Museum.

Pedoman Konservasi Koleksi Museum. Direktorat Permuseuman. 
Hooper, Eilean. and Greenhill. Museums and the Interpretation of Visual Cultural. Routledge. London and New York. 2006.

Ikram, Achadiati. Filologia Nusantara. Pustaka Jaya, Jakart, 1997.

Jaspan, M.A. Folk Literature Of South Sumatera Rejang Ka-Ga-Nga Texts. The Australian National University Camberra. 1964.

Maleong, Lexy. M. Metodologi Penelitian Kualitatif. Remaja Rosdakarya,Bandung, 2007.

Razak, Muhammadin, dkk. Pedoman Teknis Fumigasi Bahan Pustaka. Perpustakaan Nasional RI, 1998.

Sarwono, Sarwit. Pemetaan Penulisan dan Pusat Penulisan Naskah-Naskah Ulu pada Masyarakat di Provinsi Bengkulu. Laporan Penelitian, FKIP-UNIB, Bengkulu, 2006.

Masyarakat di Provinsi Bengkulu. Laporan Penelitian, FKIP-UNIB, Bengkulu. 